\title{
Severe pulmonary hypertension after the discovery of the familial primary pulmonary hypertension gene
}

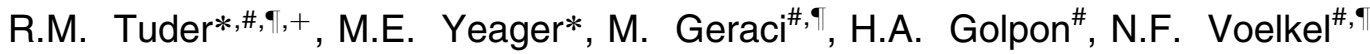

Research regarding understanding of the molecular mechanisms of pulmonary hypertension (PH) has experienced great progress in the last 3 yrs. Efforts to map the genetic susceptibility of familial primary pulmonary hypertension (FPPH) succeeded in localizing the gene site to the region $2 \mathrm{q} 32-33$, or so-called PPH1 gene site, which encompasses $\sim 3$ centimorgan $[1,2]$. This finding raised the hope that important information could be generated since the prevailing concepts concerning the pathogenesis of primary pulmonary hypertension $(\mathrm{PPH})$ have revolved around the pathophysiological roles of cellular components of vascular remodelling and abnormalities of pulmonary vascular tone control. The importance of the alterations of pulmonary vascular morphology was felt, by some, to be minimal, since they were interpreted to occur late in the disease process. Clearly, concepts were borrowed from hypoxic pulmonary vasoconstriction, yet severe $\mathrm{PH}$ is an irreversible disease with a magnitude of pulmonary hypertension not usually seen in acute or chronic hypoxia. Shortly after the FPPH locus had been announced, plexiform lesions in PPH were characterized to represent a tumour-like proliferation of a monoclonal population of endothelial cells, indicating that the endothelial cells arose from a selective growth of a single cell, whereas, in secondary $\mathrm{PH}$, endothelial cells in plexiform lesions were polyclonal [3, 4]. This finding in turn pointed towards mutational events, such as involving activation of growth-inducing kinase receptors or loss of tumour suppressor genes, as being responsible for the clonal expansion of endothelial cells in PPH [5].

Recently, germline mutations in the bone morphogenetic protein receptor II (BMPR-II) (coded within the 2q32-33 region of the PPH1 gene site) were identified in a cohort of patients with FPPH [6, 7] (fig. 1) and somatic losses of nucleotides in short stretches of repetitive mono- or dinucleotide sequences of the transforming growth factor- $\beta$ receptor II (TGF- $\beta$ RII) and Bax genes were found in endothelial cells in PPH, but not in secondary PH [9]. These findings lead to a novel hypothesis that germline and/or somatic mutations in key cell growth regulatory genes play a critical role in the development of idiopathic sporadic and familial PH. There is growing support of the concept that the dysregulation of endothelial cell growth in $\mathrm{PPH}$ has several fundamental properties in common with those seen in neoplastic processes.

The present authors believe that these recent discoveries have opened a molecular/genetic perspective for research in severe PH. However, several important questions about how these findings relate to the mechanisms, the clinical presentation, and pulmonary haemodynamics of severe $\mathrm{PH}$ still remain unanswered.

\section{Bone morphogenetic protein receptor-II mutations in familial primary pulmonary hypertension: can they explain the disease process?}

Two groups almost simultaneously reported that BMP-RII mutations occur in a cohort of patients with FPPH [6, 7]. BMPR-II mutations were identified in nine of 19 families $(47 \%)$ in the first study and in seven of eight kindreds with FPPH reported in the second study. It is important to note that the reported mutations were in one copy of the gene and were present in the germline (transmitted by parents during fertilization and therefore present in all cells). In order to cause disease, a single copy of mutated BMPR-II has to act in a dominant negative fashion, which has not been demonstrated thus far. If the mutated receptor does not inhibit the function of the wildtype receptor, it is difficult to appreciate how BMPR-II mutations would alter bone morphogenetic protein (BMP) signalling, since a predicted decrease of 25 to $75 \%$ of the receptor levels should not result in a nonfunctional receptor. In addition, not all members with BMPR-II mutations in the FPPH families have the disease. It is apparent that a heterozygous germline mutation in BMPR-II is insufficient per se to cause FPPH. Other factors or modifiers (such as ones present in cystic fibrosis patients) must be present to account for the range of severity of the disease in familial PPH cohorts (and in sporadic PPH). A "second somatic genetic hit" may be required for the development of FPPH (see later). These neoplasialike genetic events may also account for disease development in patients of FPPH not associated with

Depts of *Pathology and ${ }^{*}$ Medicine, Division of Respiratory and Critical Care Medicine; "Pulmonary Hypertension Centre, University of Colorado Health Sciences Center, CO, USA, and ${ }^{+}$Division of Cardiopulmonary Pathology, Dept of Pathology, John Hopkins University School of Medicine, MD, USA.

Correspondence: R.M. Tuder, Division of Cardiopulmonary Pathology, Dept of Pathology, John Hopkins University School of Medicine, 720 Rutland Avenue, Baltimore, MD 21205-2196, USA. Fax: 14105027813.

This work was supported by National Institute of Health grants 1RO1 HL60195-01 and 1RO1 HL60913-01, the American Heart Association, Desert Mountain Division Grant HL-00513532, and the Shirley Kiner Witham Memorial Pulmonary Hypertension Research Fund. 
a)

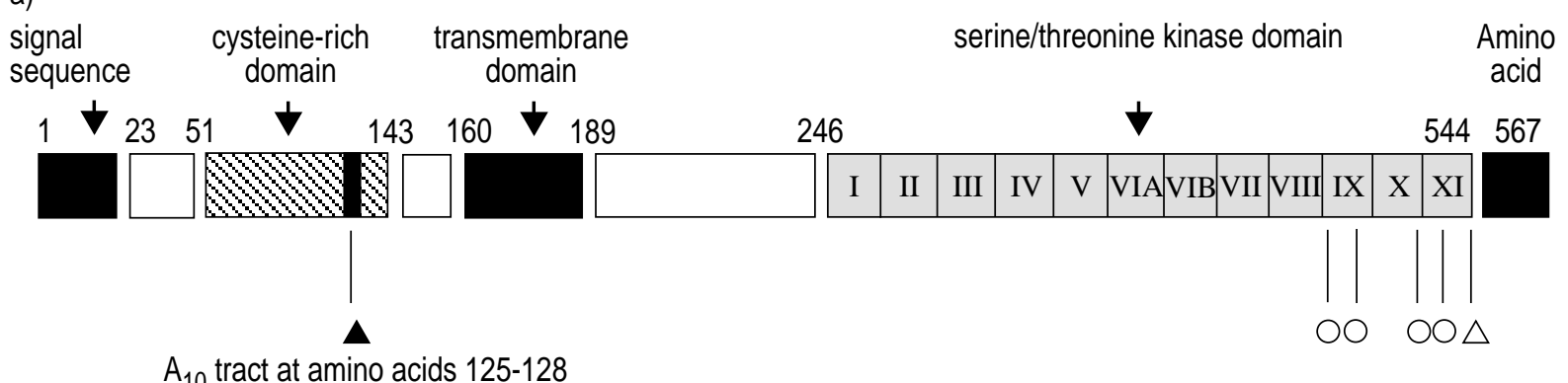

b) ligand-binding transmembrane domain
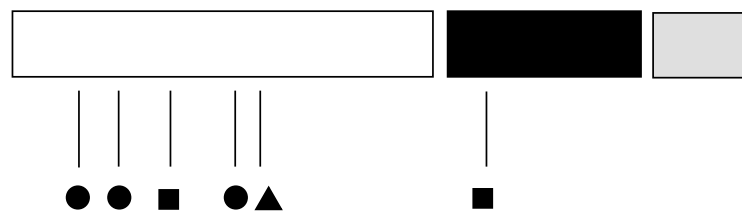

serine/threonine kinase domain

C-terminal tail

Fig. 1. - Mutations of a) transforming growth factor- $\beta$ receptor II seen in primary pulmonary hypertension plexiform lesions (filled symbols) or in colon cancer (empty symbols) and in b) bone morphogenetic protein receptor-II detected in familial primary pulmonary hypertension patients (adapted from [8]). Squares: nonsense; circles: missense; triangles: deletion/frameshift; $\mathrm{A}_{10}$ : microsatellite of 10 adenines. Roman numerals refer to subdomains of the kinase domain.

BMPR-II mutations or in the vast majority of patients with sporadic PPH, which are almost uniformly wildtype for BMPR-II.

The discovery of the association of BMPR-II mutations with FPPH was followed by a report suggesting that sporadic PPH is also associated with germline BMPR-II mutations, resulting in a similar underlying molecular defect as seen in FPPH [10]. Close examination of the data, however, indicates that this conclusion may be premature. Out of 50 patients with sporadic PPH, $13(26 \%)$ showed BMPR-II mutations. None of these patients had preliminary evidence of a family history of PPH. However, by genetic testing, three out of 50 sporadic PPH patients had paternal inheritance of BMPR-II mutations, i.e. they were patients with previously unrecognized FPPH. In addition, two out of 50 patients did not have parental samples available for testing. Therefore, in this study, BMPR-II mutations can be associated with sporadic PPH in only two out of $50(4 \%)$ patients. No attempt has been made to address which genetic events unrelated to BMPR-II underlie the development of sporadic PPH in the remaining 37 patients. However, an important observation derived from the study of THOMSON et al. [10] is that germline mutations in BMPR-II can apparently occur, albeit infrequently, in a sporadic fashion, without a background of parental transmission.

A recent study showed that asymptomatic FPPH family members (screened by microsatellite mapping: the status of BMPR-II mutations was not investigated) can have exercise-induced PH. This important information tells us either that having the FPPH gene confers, at most, a mild-to-moderate disease, or is sufficient to cause a progressive disease in patients whose malignant progression has not yet occurred [11]. Whether an abnormal vasoreactivity or early pulmonary vascular lesions can explain the exerciseinduced pulmonary hypertension in these patients is unclear and requires further study.

\section{Bone morphogenetic protein receptor-II germline muta- tions in familial primary pulmonary hypertension: can they explain pulmonary endothelial cell proliferation?}

In light of the identification of BMPR-II mutations in FPPH, it becomes important to define the role of BMPR-II signalling in the regulation of the pulmonary vasculature. Such data will illustrate how inactivating germline mutations in a single BMPR-II gene can cause growth of cells only in the lung circulation, while sparing other vascular beds (fig. 1). Current hypotheses regarding BMPR-II signalling in the pulmonary circulation have been formulated based on available knowledge derived from studies of TGF- $\beta$ signalling in vascular and nonvascular cells. However, there is no evidence that the BMP and TGF- $\beta$ signalling are mutually compensatory, i.e. that they play similar roles in cell growth control. Studies from the literature suggest that BMPR-II signalling is involved in lung branching morphogenesis [12], and abnormal BMPR-II signalling due to mutations in the noggin gene (which codes for a protein that antagonizes the BMP receptor) causes abnormal fusion of bones (proximal synphalangism and multiple synostosis). It has been postulated that BMPR-II mutations in FPPH, as seen with TGF- $\beta$ receptor mutations in cancer, may alter cellular proliferation, growth arrest, or differentiation. This may be pertinent to FPPH based on observations that BMPR-II messenger ribonucleic acid (mRNA) is expressed predominantly in the pulmonary endothelial cells in the adult lung. The only vascularrelated abnormalities ascribed to the BMPR family of signalling molecules is hereditary haemorrhagic 
telengectasia (HHT), which has been related to mutations of endoglin (HHT-1) or Alk-1 (HHT-2) genes [13]. The ligand for Alk-1 remains unknown and endoglin enhances binding of TGF- $\beta$ to its receptors. It is, however, possible that mutations of the BMPR-II gene affect the normal development of pulmonary arteries, setting the stage for the development of FPPH. If so, it is difficult to explain why the disease occurs predominantly in the third decade, and why the pulmonary circulation is the only vascular bed affected.

Regarding the pathophysiological role of BMPR-II mutations in FPPH, MAssague et al. [13] state: "Monoclonality of the hyperproliferating endothelial cells found in the plexiform lesions of familiar PPH suggests a need for the loss of the remaining wild-type BMPR-II or a cooperative mutation of a different gene, which may help explain the low prevalence of familial PPH". YeAGER et al. [9] confirmed the prediction of somatic mutations of endothelial cell genes [3] that may allow for the monoclonal cell proliferation in sporadic PPH.

\section{Endothelial cell somatic mutations in sporadic primary pulmonary hypertension: are there implications for the pathobiology of severe pulmonary hypertension?}

Given the considerations above, one can postulate that the pathogenesis of familial and sporadic PPH involves molecular alterations related to the control of cell growth, such as abnormal signalling of members of the TGF- $\beta$ superfamily in addition to BMPR-II. Over the past 8 yrs it has become clear that endothelial cell proliferation is an important and distinguishing element of many forms of severe $\mathrm{PH}$ [14], which, in its fully developed morphological presentation, results in plexiform lesions. Key cell growth or apoptosis regulatory genes contain mutation-prone microsatellites in exonic regions, which when mutated, may lead to premature termination and inactivation of the protein products. YEAGER et al. [9] have recently reported that cells in $50 \%$ of microdissected plexiform lesions in PPH, but not in normal lung tissue and not in lungs with severe $\mathrm{PH}$ induced by congenital heart malformations, are microsatellite unstable as assessed by the presence of microsatellite instability within the BAT-26 region in the deoxyribonucleic acid (DNA) repair enzyme human Mut-S homologue 2 gene. TGF- $\beta$ RII gene mutation, predicted to result in a truncated protein 100 amino acids downstream of the single nucleotide loss within exon 3 , occurred in $32 \%$ of PPH lesions sampled. However, $\sim 80 \%$ of the PPH plexiform lesions did not express the TGF- $\beta$ RII protein by immunohistochemistry [9].

Consistent with the overall microsatellite instability present in PPH lungs, the Bax mutation was found in $20 \%$ of PPH lesions, whereas wild-type Bax sequence was found in normal lungs and in lung endothelial cells of patients with secondary PH. The mutation in Bax induced by microsatellite instability was predicted to generate an inactive protein in lesional plexiform lesions [9].

Thus, in sporadic PPH, impaired TGF- $\beta$ receptor signalling and/or loss of apoptosis control due to mutated Bax could explain the monoclonal endothelial cell proliferation since both genes may be involved in endothelial cell growth control. Similar mutations might represent the second hit in cases of FPPH with BMPR-II germline mutations, as predicted by Massague and Wotton [15], in line with the paradigm of inherited cancers. However, it is important to emphasize that, in the study of YeAGER et al. [9] 17 out of $26(65 \%)$ lesions did not have mutations in either TGF- $\beta$ RII or Bax implying that mutations in other genes or additional alterations in TGF- $\beta$ signalling may allow for the clonal expansion of endothelial cells in PPH. Further screening for mutations and elucidation of the mechanisms of microsatellite instability will be of fundamental importance for the understanding of the pathobiology of severe $\mathrm{PH}$.

There is probably a very strong selection process against abnormal cell growth orchestrated by the host (fig. 2). Insight into how this selection process operates was reported recently by IonOv et al. [16] who demonstrated that colon cancer cells with heterozygous Bax mutations (a loss or an addition of a Guanine in a microsatellite site of a stretch of eight Guanines), when injected into nude mice, show preferential growth of a homozygous mutated population (which does not express Bax) instead of those cells that are either heterozygous or wild-type for the Bax microsatellite sequence of eight guanines (BaxG8), and consequently, capable of expressing Bax protein. Therefore, microsatellite instability within genes involved in regulation of cell growth and apoptosis can afford cells with the capacity to overcome a strong selection pressure in vivo and thus to expand in a clonal pattern. It follows that plexiform lesion endothelial cells have to overcome a similarly strong selective pressure against the development of clusters of proliferated endothelial cells, in essence, they have to overcome a vascular protective pressure that reinforces the "law of the endothelial cell monolayer" (fig. 2).

The occurrence of an endothelial proliferative phenotype may also be triggered by pulmonary vascular inflammation and/or endothelial cell death. Perivascular inflammation has been reported in lungs of patients with severe $\mathrm{PH}[14,17]$ and endothelial cell apoptosis has been observed in an animal model with severe $\mathrm{PH}$ triggered by the combination of chronic hypoxia and vascular endothelial growth factor (VEGF) receptor blockade [18]. Inflammation and oxidative stress may induce genetic instability as shown for the increased risk of colon cancer in the setting of ulcerative colitis [19].

\section{Pulmonary hypertension and the transforming growth factor- $\beta$ superfamily}

A recent comprehensive review of the TGF- $\beta$ gene superfamily by Massague and WotTon [15] emphasizes the central role of $\mathrm{Smad}_{4}$ in the regulation of TGF- $\beta$ family signalling. The Smads (the mammalian counterpart of the Drosophila mdd or mothers against decapentaplegic), together with cofactors like c-jun of the AP1 complex transcription factor, and Hox gene transcription factors (also known as clustered or class I homeobox genes), accomplish the 


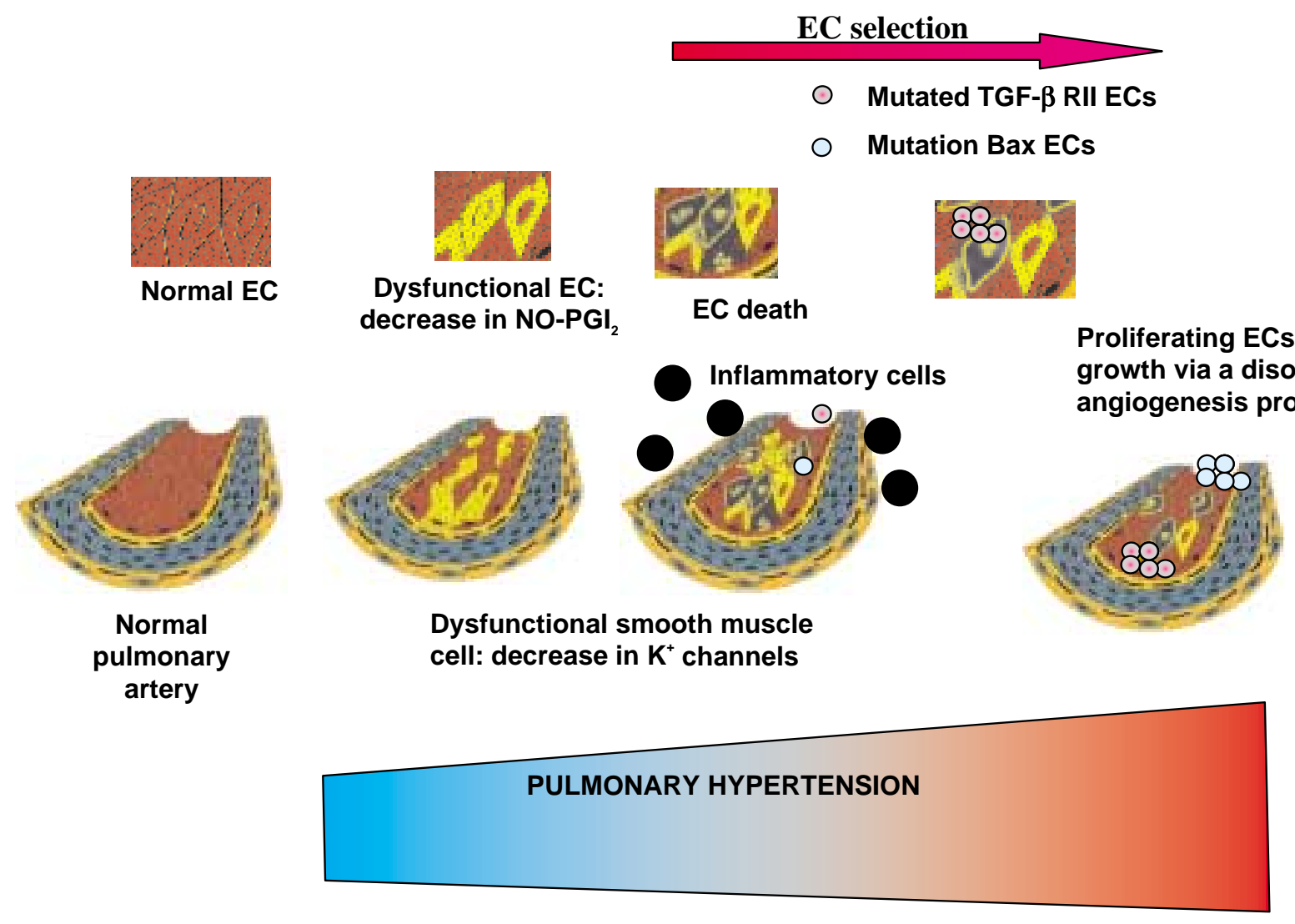

Fig. 2. - Hypothesis of somatic mutations in primary pulmonary hypertension. There is a strong pressure to maintain the normal monolayer structure of the pulmonary endothelium. However, possibly triggered by normal lung endothelial cell injury followed by apoptosis, or due to the free radical deoxyribonucleic acid damage triggered by perivascular inflammatory cells, the pulmonary endothelial cells (ECs) undergo microsatellite mutations in cell growth regulatory genes such as transforming growth factor- $\beta$ receptor II (TGF- $\beta$ RII) or Bax, resulting in a clonal expansion proliferation of ECs in primary pulmonary hypertension. NO: nitric oxide; PGI $_{2}$ : prostacyclin.

transcription of the target genes responsible for cell growth control (and possibly cell phenotype) [20]. Both BMPR-II and TGF- $\beta$ RII signals intersect at the recruitment of $\mathrm{Smad}_{4}$. Inactivating mutations in $\mathrm{Smad}_{4}$ have been found in pancreatic and gastrointestinal cancers and it is of great interest that in the Hs766T human pancreatic cancer cell line, inactivating $\mathrm{Smad}_{4}$ mutations have been shown to induce an angiogenic (endothelial cell proliferative) phenotype, with upregulation of VEGF and downregulation of thrombospondin by the cancer cells. The antiangiogenic effect of $\mathrm{Smad}_{4}$ was independent of TGF- $\beta$ / TGF- $\beta$ receptor-mediated signalling [21].

It is now clear that severe PH constitutes a group of diseases, where the endothelial cell proliferation in plexiform lesions can develop via a monoclonal or a polyclonal endothelial cell growth. The schematic in figure 3 organizes the landscape of severe $\mathrm{PH}$

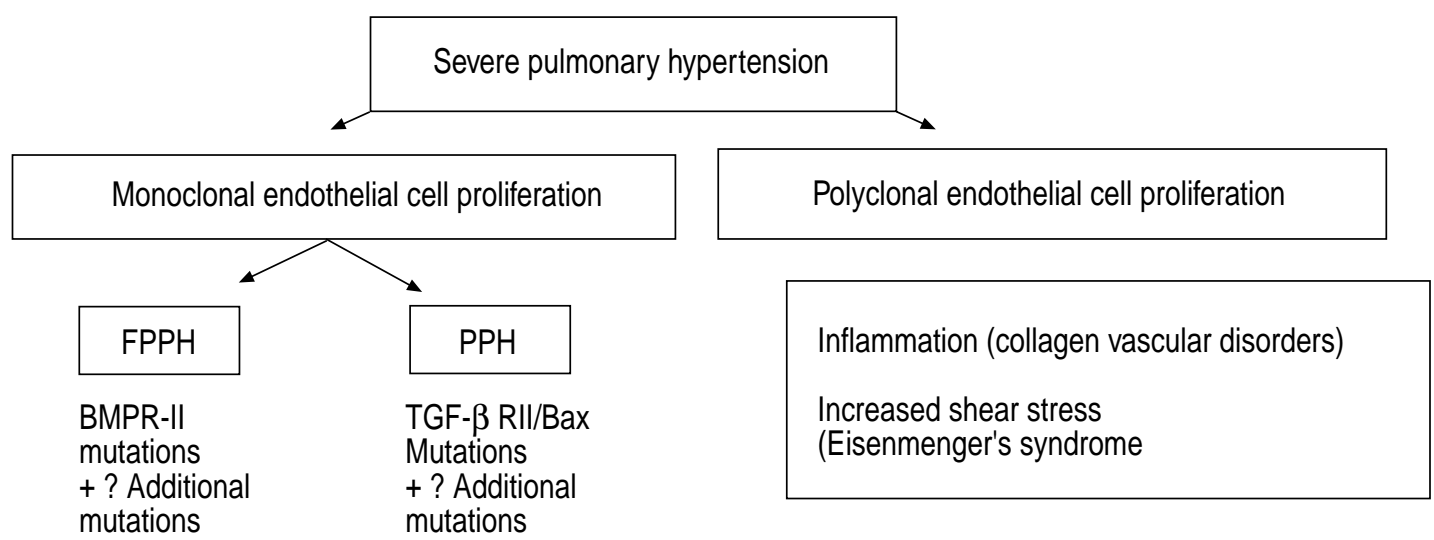

Fig. 3. - Characterization of severe pulmonary hypertension with respect to clonality of endothelial cell proliferation and presence of mutations. FPPH: familial primary pulmonary hypertension (PPH); TGF- $\beta$ RII: transforming growth factor- $\beta$ receptor II; BMPR-II: bone morphogenetic protein receptor-II. 
disorders that are associated with endothelial cell proliferation. FPPH can be associated with germline mutations of the BMPR-II, which, by themselves, are probably insufficient to cause angioproliferative disease. Somatic mutations in endothelial cell TGF- $\beta$ RII and/or Bax genes within plexiform lesions in PPH may be acquired in the sporadic form of the disease and, if present in FPPH lungs with BMPR-II mutation, may represent the second hit responsible for endothelial cell proliferation. If mutations in TGF- $\beta$ RII causes haploinsufficiency, then there are additional, as yet uncharacterized gene defects, which are necessary for the development of disease. These gene defects may involve mutations in other growth control genes or epigenetic silencing of key growth regulatory gene products. Heterozygous mutations in TGF- $\beta$ RII may be sufficient to cause monoclonal endothelial cell proliferation if they result in a dominant negative receptor, which abrogates the function of the remaining wild-type allele.

\section{Summary}

The recent discoveries of the familial primary pulmonary hypertension gene and somatic mutations in key cell growth and cell death regulatory genes in primary pulmonary hypertension have added a new dimension to severe pulmonary hypertension research. These findings have already impacted on how the disease is viewed, and ultimately, how severe pulmonary hypertension is diagnosed and treated. However, this new information raises several fundamental questions related to the role of bone morphogenetic protein receptor signalling in the control of lung vascular cell function. Furthermore, additional genes and gene products may also be involved in the pathogenesis of the disease. The way severe pulmonary hypertension is viewed and studied is on the verge of shifting from a vasoconstrictive to a cell growth paradigm.

\section{References}

1. Nichols WC, Koller DL, Slovis B, et al. Localization of the gene for familial primary pulmonary hypertension to chromosome 2q31-32. Nat Genet 1997; 15: $277-280$.

2. Morse JH, Jones AC, Barst RJ, Hodge SE, Wilhelmsen KC, Nygaard TG. Mapping of familial primary pulmonary hypertension locus (PPH1) to chromosome 2q31-q32. Circulation 1997; 95: 2603-2606.

3. Lee SD, Shroyer KR, Markham NE, Cool CD, Voelkel NF, Tuder RM. Monoclonal endothelial cell proliferation is present in primary but not secondary pulmonary hypertension. J Clin Invest 1998; 101: 927-934.

4. Tuder RM, Radisavljevic Z, Shroyer KR, Polak JM, Voelkel NF. Monoclonal endothelial cells in appetite suppressant-associated pulmonary hypertension. Am J Respir Crit Care Med 1998; 158: $1999-2001$

5. Voelkel NF, Cool CD, Lee SD, Wright L, Geraci MW, Tuder RM. Primary pulmonary hypertension between inflammation and cancer. Chest 1999; 114: $225 \mathrm{~S}-230 \mathrm{~S}$.
6. The International PPH Consortium, Lane KB, Machado RD, Pauciulo MW, et al. Heterozygous germline mutations in BMPR2 encoding a TGF- $\beta$ receptor cause familiar pulmonary hypertension. Nat Genet 2000; 26: $81-84$.

7. Deng Z, Morse JH, Slager SL, et al. Familial Primary Pulmonary Hypertension (Gene PPH1) is Caused by Mutations in the Bone Morphogenetic Protein Receptor-II Gene. Am J Hum Genet 2000; 67: 737-744.

8. Markowitz S. TGF-beta receptors and DNA repair genes, coupled targets in a pathway of human colon carcinogenesis. Biochim Biophys Acta 2000; 1470: M13-M20.

9. Yeager ME, Halley GR, Golpon HA, Voelkel NF, Tuder RM. Microsatellite instability of endothelial cell growth and apoptosis genes within plexiform lesions in primary pulmonary hypertension. Circ Res 2001; 88: E8-E11.

10. Thomson JR, Machado RD, Pauciulo MW, et al. Sporadic primary pulmonary hypertension is associated with germline mutations of the gene encoding BMPR-II, a receptor member of the TGF-beta family. J Med Genet 2000; 37: 741-745.

11. Grunig E, Janssen B, Mereles D, et al. Abnormal pulmonary artery pressure response in asymptomatic carriers of primary pulmonary hypertension gene. Circulation 2000; 102: 1145-1150.

12. Cardoso WV. Transcription factors and pattern formation in the developing lung. Am $J$ Physiol 1995; 269: L429-L442.

13. Massague J, Blain SW, Lo RS. TGFbeta signaling in growth control, cancer, and heritable disorders. Cell 2000; 103: 295-309.

14. Tuder RM, Groves BM, Badesch DB, Voelkel NF. Exuberant endothelial cell growth and elements of inflammation are present in plexiform lesions of pulmonary hypertension. Am J Pathol 1994; 144: 275-285.

15. Massague J, Wotton D. Transcriptional control by the TGF-beta/Smad signaling system. EMBO J 2000; 19: $1745-1754$.

16. Ionov Y, Yamamoto H, Krajewski S, Reed JC, Perucho M. Mutational inactivation of the proapoptotic gene BAX confers selective advantage during tumor clonal evolution. Proc Natl Acad Sci USA 2000; 97: $10872-10877$.

17. Caslin AW, Heath D, Madden B, Yacoub M, Gosney JR, Smith P. The histopathology of 36 cases of plexogenic pulmonary arteriopathy. Histopathology 1990; 16: 9-19.

18. Taraseviciene-Stewart L, Kasahara Y, Alger LA, et al. Inhibition of the VEGF receptor-2 combined with chronic hypoxia causes cell death-dependent pulmonary endothelial cell proliferation and severe pulmonary hypertension. FASEB J 2001; 15: 427-438.

19. Loeb KR, Loeb LA. Genetic Instability and the Mutator Phenotype: Studies in Ulcerative Colitis. Am J Pathol 1999; 154: 1621-1626.

20. Shi X, Yang X, Chen D, Chang Z, Cao X. Smad1 interacts with homeobox DNA-binding proteins in bone morphogenetic protein signaling. $\mathrm{J}$ Biol Chem 1999; 274: 13711 - 13717.

21. Schwarte-Waldhoff I, Volpert OV, Bouck NP, et al. Smad4/DPC4-mediated tumor suppression through suppression of angiogenesis. Proc Natl Acad Sci USA 2000; 97: 9624-9629. 